FRANCISCA OLIVEIRA DA CONCEIÇÃO

A UTILIZAÇÃO DA FIBRA DO BURITI COMO UMA TÉCNICA DE INOVAÇÃO NA DISCIPLINA DE ARTES NA ESCOLA DE ENSINO MÉDIO PROFESSOR

FLODOARDO CABRAL 
FRANCISCA OLIVEIRA DA CONCEIÇÃO

\section{A UTILIZAÇÃO DA FIBRA DO BURITI COMO UMA TÉCNICA DE INOVAÇÃO NA DISCIPLINA DE ARTES NA ESCOLA DE ENSINO MÉDIO PROFESSOR FLODOARDO CABRAL}

Trabalho de Conclusão do Curso de Artes Visuais, Habilitação em Licenciado do Departamento de Artes Visuais do Instituto de Artes Visuais da Universidade de Brasília.

Orientador: Prof. Dr. Belidson Dias

Co-Orientadora Prof ${ }^{\mathrm{a}}$. MsC Adriana Vignoli 
SUMÁRIO

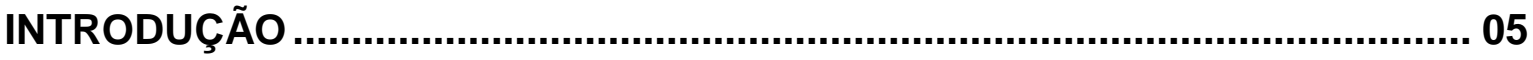

1 REVIVENDO A HISTÓRIA DO ENSINO DE ARTES ........................................ 09

1.1 Proposta Pedagógica........................................................................ 13

1.2 A Fibra do Buriti como Técnica de Inovação na Sala de Aula .....................17

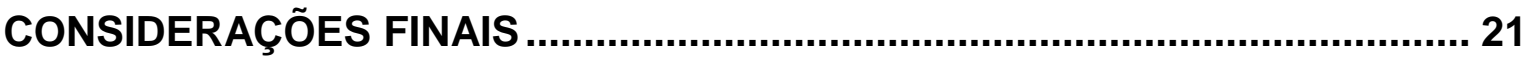

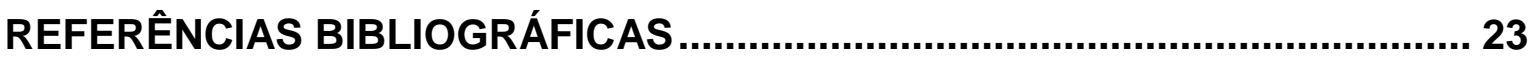




\section{FIGURAS}

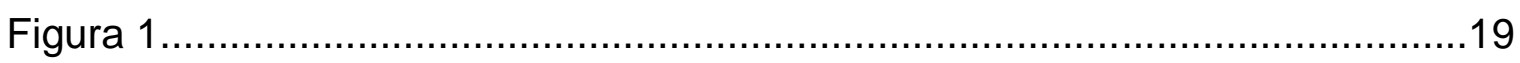

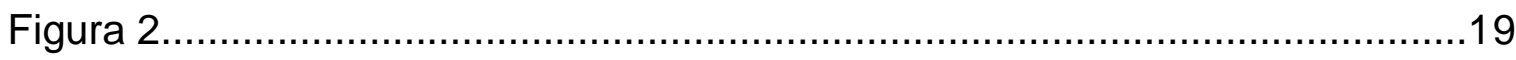




\section{RESUMO}

O presente Trabalho de Conclusão de Curso discute a utilização da fibra do buriti como uma técnica de inovação na disciplina de Artes na Escola de Ensino Médio Professor Flodoardo Cabral. A abordagem se dá a partir da problemática de como propor uma prática pedagógica que modifique a relação dos alunos com a aula de artes, produzindo resultados voltados para a formação da cidadania. A pesquisa foi realizada com a turma do primeiro ano do Ensino Médio. Utilizou-se a observação nas aulas de arte como principal instrumento de pesquisa e foi possível constatar as metodologias de ensino utilizadas no ensino de arte, bem como propor novas metodologias a partir da utilização da fibra de buriti. Pode-se concluir que o trabalho com a fibra de buriti em sala de aula se insere no debate sobre a importância de 0 ensino de artes estar em constante interação com a realidade social dos alunos.

Palavras-chaves: fibra de buriti; ensino de artes; propostas metodológicas. 


\section{INTRODUÇÃO}

A prática pedagógica de arte no Ensino Médio deve contribuir para o fortalecimento da experiência sensível e inventiva dos estudantes e para o exercício da cidadania e da ética construtora de identidades artísticas. Como destaca o Projeto Pedagógico (2010) da Escola Estadual de Ensino Médio Professor Flodoardo Cabral, objeto desta pesquisa, "a arte compõe a área de linguagens, códigos e suas tecnologias enquanto linguagem expressivo-comunicativa impregnada de valores culturais e estéticos" (2010, p.70)

O alcance dessa perspectiva se faz dando continuidade aos conhecimentos de arte desenvolvidos na educação infantil e fundamental em artes visuais - dança música e teatro - ampliando, assim, os saberes. Nesse sentido, esta pesquisa tem por objetivo mostrar que o artesanato pode ser uma excelente ferramenta de dinamização da metodologia para o ensino de artes, além de destacar a importância da diversificação do artesanato regional do Estado do Acre para os alunos do $1^{\circ}$ ano da referida escola.

A pesquisa se embasou na seguinte problemática: como propor uma prática pedagógica que modifique a relação dos alunos com a aula de artes, produzindo resultados voltados para a formação da cidadania? Dessa forma, se visa a contribuir para a realização de atividades artísticas em sala de aula de forma mais dinâmica e prazerosa, objetivando a construção de uma experiência reflexiva e voltada para a transformação do indivíduo através da arte. Pelo contato com a produção de materiais artesanais de fibra de buriti e observando o cotidiano e a dinâmica das comunidades produtoras, entende-se que se faz necessário discutir a perspectiva de construção de novos jeitos de ver e entender a arte, compreendendo o multiculturalismo como fator de produção de cidadania.

Segundo Barbosa "o multiculturalismo em arte/educação é, e deve ser continuamente, um processo para encorajar a justiça e o desenvolvimento social, tornando as comunidades construtivas" (2008, p.266). O multiculturalismo considera a história como um perene processo de mudanças, permitindo que conhecimentos antigos entrecruzem-se com os novos, promovendo adaptações aos novos ambientes e circunstâncias e novas formas de expressão. Esta pesquisa engloba o 
multiculturalismo no sentido de que busca aproximar valores culturais diversificados em uma proposição de construção da cidadania através da arte.

Espera-se que, através do contato com o artesanato em fibra do buriti, os alunos do 1ํ Ano dessa escola de Ensino Médio tenham contato com produtos regionais produzidos de forma sustentável, compreendendo perspectivas conceituais e atitudinais. Assim, ocorrerá a transformação dos conceitos em atitudes práticas observáveis e mensuráveis pelo educador de produção artística e artesanal, podendo se transformar em fonte de renda e produção cultural de grande significado. Isso, por fazer parte da cultura local do seu povo, observando o aperfeiçoamento de técnicas de trabalho anteriormente executadas de forma mais rudimentar.

Esta pesquisa busca novas técnicas de aprendizado no mundo da arte para aproximar a comunidade escolar à sociedade através das experiências e técnicas colocadas em prática pelos alunos, por meio da arte com a fibra do buriti. Essas experiências abrem espaço para a experiência coletiva de participação e valorização do artesanato, como também um contato com a natureza, buscando o conhecimento de educação ambiental, no sentido de utilizar materiais da natureza sem degradar o meio ambiente e observar formas produtivas sustentáveis.

Portanto, além de proporcionar aos educandos uma aula de arte prazerosa e divertida com a inserção de novas práticas e novas atividades, indica a fibra do buriti como uma forte renda de economia para eles e suas famílias, bem como instrumento de valorização da cultura local. Dessa forma, a arte na região precisa ser mais valorizada, para que os artesãos sejam motivados e produzam cada vez mais e com excelente qualidade suas obras de arte. Isto é reforçado nas idéias de Eloí Calage:

[...] a pouca oferta de emprego tem despertado nas pessoas o desejo pelo trabalho autônomo, ou que garanta um dinheiro extra para melhorar a qualidade de vida ou aumentar o orçamento doméstico. Ao procurar o artesanato, as pessoas encontram mais do que um ganho ou um "bico". Eles encontram uma atividade fascinante, uma prática que entusiasma (CALAGE, 2002, p. 08).

Assim, pode-se entender que a atividade artesanal é mais do que trabalho, é algo que fascina e vai além da obrigação do fazer por fazer ou porque precisa ser feito para garantir o pão de cada dia. Nessa perspectiva, é que se vislumbra a 
proposta do ensino de artes à qual a problemática da pesquisa visa: a percepção de que as práticas do ensino de arte são muito mais do que disciplina obrigatória do currículo, devendo ser ensinada para garantir ao aluno passar de ano, mas sim, que seja um ensino que o fascine para a vida e o ajude a olhar o mundo com o olhar de admiração e gratidão, que o ajude a ser mais humano e cidadão.

Nesse sentido, pretende-se destacar a importância dos recursos naturais no campo das artes visuais e abrir perspectivas para que o artesanato se torne uma arte mais qualificada. Vale ressaltar que, segundo Fusari "o estudo das Artes Visuais inclui tradicionalmente o desenho, a pintura, a gravura, a escultura, a arquitetura, $o$ desenho industrial" (2001, p.77). Portanto, se concebe a fibra de buriti como recurso para a confecção de modalidades diversificadas de artes visuais.

Portanto, a escolha do uso da fibra do buriti como mecanismo de inovação técnica das aulas de arte foi devido à abundância e à boa qualidade na confecção de artesanato e pelo fácil acesso na região, conforme explicita Patrícia Shanley, (2005, p.183). No Acre, política de incentivos ao aproveitamento da espécie vem sendo efetivadas. No Vale do Juruá, os extrativistas processam a poupa de buriti para obtenção de óleo. Objetivo dessa experiência pioneira é a comercialização em grande escala. Além do que destaca Shanley, vale ressaltar a importância de aproveitar os recursos naturais como uma forma de preservação do meio ambiente, pois utilizando os elementos da natureza onde o homem não retire mais do que o necessário, mantém a rica utilidade destes elementos e pode ser utilizado como fonte de renda.

Portanto, a pesquisa se dá a partir da metodologia de abordagem de pesquisa qualitativa através da coleta de dados com os alunos nos locais de produção do artesanato, enquetes e entrevistas com os produtores e artesãos, levantamento de imagens e catalogação de produtos em um banco de dados visuais, identificação do itinerário comercial desde a produção até a comercialização final. Os estudos em pesquisa qualitativa, conforme GODOY (1995, p. 62) difere-se das demais em virtude da utilização do ambiente natural como fonte direta de dados, do caráter descritivo, do significado que as pessoas dão às coisas e à sua vida como preocupação do investigador e do enfoque indutivo.

Esse trabalho se embasou em autores como Barbosa, que aborda 0 multiculturalismo e a reforma escolar por meio da arte/educação; Fusari, que trata da 
arte na educação escolar; Calage, que aborda a importância do artesanato; Godoy, que define a metodologia utilizada na pesquisa, Ana Mae Barbosa, referência no ensino de artes no Brasil, entre outros e das legislações pertinentes ao tema como os Parâmetros Curriculares Nacionais para o Ensino de Arte e a Lei de Diretrizes e Bases da Educação. 


\section{REVIVENDO A HISTÓRIA DO ENSINO DE ARTES}

A arte na escola era vista, ainda há pouco tempo, como um descanso para os professores e alunos que depois de uma aula cansativa, como matemática ou português, inseriam um horário de arte, em que o professor pedia para o aluno pegar seu caderno de desenho e desenhar qualquer coisa que quisesse. Depois de tantas lutas esse conceito de arte apenas recreativo e sem finalidade ou objetivos definidos vem mudando, graças às reflexões de uma parcela de professores, pesquisadores e da própria sociedade.

$\mathrm{Na}$ escola tradicional, valorizavam-se, principalmente, as habilidades manuais, os "dons artísticos", os hábitos de organização e precisão, mostrando ao mesmo tempo uma visão utilitarista e imediatista da arte. Os professores trabalhavam com exercícios e modelos convencionais selecionados por eles em manuais e livros didáticos. $O$ ensino de Artes era voltado essencialmente para 0 domínio técnico, mais centrado na figura do professor. Competia a ele "transmitir" aos alunos os códigos, conceitos e categorias, ligados a padrões estéticos que variavam de linguagem para linguagem, mas que tinha em comum sempre a reprodução de modelos.

As atividades de teatro e dança somente eram reconhecidas quando faziam parte das festividades escolares na celebração de datas como Natal, Páscoa ou Independência, ou nas festas de final de período escolar. O teatro era tratado com uma única finalidade: a da apresentação. As crianças decoravam os textos e os movimentos cênicos eram marcados com rigor. Em Música, a tendência tradicionalista teve seu representante máximo no Canto Orfeônico, projeto preparado pelo compositor Heitor Villa-Lobos na década de 30 . Esse projeto constitui referência importante por ter pretendido levar a linguagem musical de maneira consistente e sistemática a todo o País. O Canto Orfeônico difundia idéias de coletividade e civismo, princípios condizentes com o momento político de então.

Depois de cerca de trinta anos de atividades em todo o Brasil, o Canto Orfeônico foi substituído pela Educação Musical, criada pela Lei de Diretrizes e Bases da Educação Brasileira de 1961, vigorando efetivamente a partir de meados da década de 60. No período que vai dos anos 20 aos dias de hoje, faixa de tempo concomitante àquela em que se assistiu a várias tentativas de se trabalhar a arte 
também fora das escolas, vive-se o crescimento de movimentos culturais, anunciando a modernidade e vanguardas. Foi marcante para a caracterização de um pensamento modernista a "Semana de Arte Moderna de São Paulo", em 1922, na qual estiveram envolvidos artistas de várias modalidades: artes plásticas, música, poesia, dança, etc.

Nessa época, a atividade artística não era incluída nas escolas públicas elementares. O ensino de arte era exclusividade da Academia Imperial de Belas Artes. A metodologia do ensino de arte tinha como fundamento principal o desenho, primeiramente de partes do corpo humano e num estágio posterior a observação de bustos de gesso para os exercícios de luz e sombra. A prática com os pincéis acontecia numa etapa mais avançada, começando com a cópia de um detalhe de algum mestre da pintura e depois com os estudos compositivos a tinta até a produção de uma pintura do início ao fim, em que se retiravam todos os vestígios de imperfeição.

Ademais, a arte foi incluída no currículo escolar desde 1971, com o nome de Educação Artística, através da Lei de Diretrizes e Bases da Educação Nacional, ainda como "atividade educativa" e não como disciplina, sofrendo em 1988, a ameaça de ser excluída do currículo, a partir das discussões sobre a Nova Lei de Diretrizes e Bases. Por não ser considerada uma disciplina, a Educação Artística não podia reprovar nenhum aluno e fazia com que eles não tivessem interesse nenhum em sua prática, fazendo com que ela fosse vista como apenas uma aula de desenho e o professor visto como o organizador de festas e eventos na escola.

No entanto, com a Lei de Diretrizes e Bases da Educação - LDB de 1996 (lei no. 9.394/96), revogam-se os arranjos anteriores e a Arte é considerada disciplina obrigatória na educação básica conforme o seu artigo 26 , parágrafo $2^{2}$, que diz que o ensino de arte constituiria componente curricular obrigatório, nos diversos níveis da educação básica, visando ao desenvolvimento cultural dos alunos.

Portanto, com esta nova lei entende-se que o professor da disciplina de arte deve ter uma boa formação e ser bem preparado para tal. Assim, poderá ser reconhecido e com capacidade de trazer um ensino de qualidade para o aluno, e, no caso do ensino de artes, é necessário que ele esteja em constante atualização para que não forneça informações descontextualizadas e ultrapassadas na sociedade. 
Nesse sentido, a área de Arte dentro dos Parâmetros Curriculares Nacionais situa-se como um tipo de conhecimento que envolve tanto a experiência de apropriação de produtos artísticos quanto ao desenvolvimento da competência de configurar significações por meio da realização de formas artísticas. Segundo os PCN:

[...] entende-se que aprender arte envolve não apenas uma atividade de produção artística pelos alunos, mas também a conquista da significação do que fazem, pelo desenvolvimento da percepção estética, alimentada pelo contato com o fenômeno artístico visto como objeto de cultura através da história e como conjunto organizado de relações formais (PCN, 1996, p.44).

Seja por força das leis educacionais, tais como a Lei de Diretrizes e Bases LDB/96 e PCN, seja pelo avanço de pesquisas na área, ou ainda, graças aos esforços de "uma meia dúzia" de professores preocupados com a melhoria educacional, o ensino de artes em algumas escolas vem mudando gradativamente e deixando de ser apenas desenho ou pintura para dar lugar às manifestações culturais de uma determinada comunidade. Atualmente, podemos ver escolas trabalhando arte com projeto de danças, teatros, leitura de obras literárias, projetos de construção de brinquedos com materiais recicláveis, entre outros.

Assim, essa proposição abre possibilidades para que o artesanato produzido com fibras de buriti seja integrado à sociedade, valorizando seu trabalho e mostrando a capacidade criadora tanto do educador como do educando, bem como a troca de conhecimentos e experiências, valorizando a matéria prima empregada no artesanato.

O desenvolvimento do ensino de artes nessa perspectiva, além de contribuir para uma postura de formação de objetivos e valores sociais democráticos, permite ao educando uma construção mais ampla do conceito de arte, como destaca Barbosa:

Os objetivos e valores democráticos devem: ser fundamentados na vida do estudante; promover ferramentas para a visão crítica de todos os sistemas sociais e culturais; estabelecer ambiente seguro no qual seja feito uma inquisição crítica; incitar investigação de preconceito; apresentar como objetivo a justiça para todos; investir no envolvimento participativo e experimental e ser otimista, alegre, bom, visionário, positivo, academicamente ativista, rigoroso, integrado, culturalmente sensitivo e utilizar recursos comunitários. (2008, p.267). 
Por isso, este trabalho envolve a ampliação do conceito de arte para uma visão ampla e integrada com a democracia, com a construção do pensamento crítico e de valores integrados de convivência social.

Como se pode observar, o ensino de arte envolve praticamente todas as áreas do conhecimento, pois este propõe 0 respeito à diversidade cultural e o desenvolvimento de habilidades artísticas. Além disso, o ensino de artes favorece ao aluno relacionar-se criadoramente com as outras disciplinas do currículo. Por exemplo, o aluno que conhece arte pode estabelecer relações mais amplas quando estuda um determinado período histórico. Um aluno que exercita continuamente sua imaginação estará mais habilitado a construir um texto, a desenvolver estratégias pessoais para resolver um problema matemático. Além disso, conhecendo a arte de outras culturas, o aluno poderá compreender a relatividade dos valores que estão enraizados nos seus modos de pensar e agir, que pode criar um campo de sentido para a valorização do que lhe é próprio e favorecer abertura à riqueza e à diversidade da imaginação humana.

Ademais, esse aluno torna-se capaz de perceber sua realidade cotidiana mais vivamente, reconhecendo objetos e formas que estão à sua volta no exercício de uma observação crítica do que existe na sua cultura, podendo criar condições para uma qualidade de vida melhor. Uma função igualmente importante que o ensino da arte tem a cumprir diz respeito à dimensão social das manifestações artísticas. A arte de cada cultura revela o modo de perceber, sentir e articular significados e valores que governam os diferentes tipos de relações entre os indivíduos na sociedade. A arte solicita a visão, a escuta e os demais sentidos como portas de entrada para uma compreensão mais significativa das questões sociais. Essa forma de comunicação é rápida e eficaz, pois atinge o interlocutor por meio de uma síntese ausente na explicação dos fatos.

Segundo Ferraz e Fusari (1999), para que exista a construção de práticas do ensino de arte que garantam conhecimentos estéticos, artísticos e o diálogo com as necessidades e interesses dos alunos e de sua comunidade, há a necessidade que o educador cultive a consciência histórica e a reflexão crítica para imbricar a prática na teoria, isto é, conhecer arte e saber ensinar arte. Sendo assim, torna-se essencial mencionar a formação do professor de artes, uma vez que, se ele não for bem preparado, não poderá preparar aulas diversificadas, levando sempre algo novo 
para os alunos fazerem, mostrando a importância de cada conteúdo para a sua realidade. Para se ter resultado eficaz no processo de ensino e aprendizagem, nada melhor que fazer relação dos conteúdos com o contexto social, cultural e econômico da sociedade em que o aluno está inserido.

De acordo com os PCN, Parâmetros Curriculares Nacionais, que são documentos referenciais de qualidade para o ensino Fundamental e Médio, na primeira metade do século XX, as disciplinas Desenho, Trabalhos Manuais, Música e Canto Orfeônico faziam parte dos programas das escolas primárias e secundárias, concentrando o conhecimento na transmissão de padrões e modelos das culturas predominantes.

É importante que os alunos compreendam o sentido do fazer artístico, que suas experiências de desenhar, cantar, dançar ou dramatizar não são atividades que visam a distraí-los da "seriedade" das outras disciplinas. Ao fazer e conhecer arte, o aluno percorre trajetos de aprendizagem que propiciam conhecimentos específicos sobre sua relação com o mundo. Além disso, desenvolve potencialidades como: percepção, observação, imaginação e sensibilidade. Essas competências podem alicerçar a consciência do seu lugar no mundo e também contribuem inegavelmente para sua apreensão significativa dos conteúdos das outras disciplinas do currículo.

\subsection{Proposta Pedagógica}

Talvez devido à limitação do modo como é colocado o conhecimento histórico e cultural das experiências estéticas da humanidade, o ensino de artes nas escolas tem apresentado, historicamente, certa precariedade e limitações. Portanto, a implantação de qualquer mudança no ensino dessa disciplina deve se preocupar com as relações socioculturais e as condições propícias para a aprendizagem contextualizada. Desse modo, para obter uma educação com qualidade, o trabalho inicial é o do professor reflexivo e sensível capaz de dialogar com as linguagens, a história da arte e do ensino. Este profissional deve ter segurança ao escolher conteúdos e objetivos artísticos bem definidos em suas propostas, afinados com as realidades das diferentes comunidades. 
A arte é um modo privilegiado de conhecimento e aproximação entre indivíduos de culturas distintas, pois favorece o reconhecimento de semelhanças e diferenças expressas nos produtos artísticos e concepções estéticas, num plano que vai além do discurso verbal. Uma criança da cidade, ao observar uma dança indígena, estabelece um contato com o índio que pode revelar mais sobre o valor e a extensão de seu universo do que uma explanação sobre a função do rito nas comunidades indígenas. Trazendo para a realidade, os alunos podem pensar em um aspecto da cultura em que está inserido e transpor para a atividade da disciplina em sala de aula.

$O$ entendimento de que o ensino de artes precisa envolver o aluno com sua realidade cultural e social tem como referência os escritos de Barbosa, que ressaltam a importância de trabalhar arte/educação baseada na comunidade. Essa ideia, embora não seja muito difundida no Brasil "[...] tem recebido grande atenção $e$ ganhado popularidade entre alguns educadores nos Estados Unidos durante os últimos anos" (2008, p.227).

Nessa perspectiva, durante as observações em sala de aula foi possível perceber que o ensino de artes ainda está muito desvinculado da realidade do aluno. As observações foram feitas em dois momentos da aula: em uma, houve a predominância do desenho e da pintura. No primeiro momento como desenho livre e no segundo, o desenho tinha o objetivo de expressar o entendimento de uma leitura. Em outra aula observada trabalhou-se os conteúdos de música, dança e pintura em tela. Contudo, ficou claro que a parte de artesanato a partir dos recursos naturais é pouco ou nada explorada, algo pouco compreensível, haja vista a riqueza que temos em nossa região desses materiais, de modo especial, a fibra de buriti. E como ressalta Barbosa (2008), o modelo de arte/educação baseado na comunidade propõe a valorização da cultura local e dos recursos existentes e disponíveis na comunidade.

Conforme mencionado, percebe-se certa lacuna do ensino de artes ao que se refere à utilização de recursos naturais e de valorização da cultura local. Essa lacuna possibilita aberturas para se propor novas metodologias para o ensino de artes. Por isso, aproveitando o ensejo, a pesquisa sugere uma proposta pedagógica.

Nessa proposta, as aulas acontecerão em dois momentos: uma parte teórica e outra prática. Na teoria será possível conhecer a história da palmeira, sua 
importância para o meio ambiente e a lei municipal que protege essa palmeira contra as derrubadas. Nessas aulas entrarão em discussão os valores e objetivos sociais democráticos, pois, à medida que o aluno entende as questões econômicas, políticas e sociais que estão por trás das leis que protegem a palmeira e entendem o seu valor comercial, poderão construir uma nova visão frente à economia local e os cuidados com o meio ambiente, além de possibilitar a valorização do que é seu, ou seja, da sua região.

Já na parte prática, as aulas permitirão o contato com os artistas local e com seu trabalho, e os alunos terão espaço para produzir suas próprias obras de arte. Desse modo, será feito contato formal e informal com os artesãos da localidade, a expressão artística nas mais diversas formas: poesia sobre a exuberância da palmeira e sua fonte de geração de água e renda. Além disso, eles produzirão e apresentarão teatro sobre a importância da preservação da palmeira que, embora se encontre em abundancia, poderá vir à extinção se não for usada corretamente, a partir do manejo sustentável. Os alunos também confeccionarão artesanatos com a fibra de buriti, tais como, brinquedos, bijuterias, bolsas, vasos, chapéus, entre outros.

O estudo do itinerário produtivo e comercial permitirá um maior entendimento da dinâmica econômica da região e da construção de sujeitos ativos e participativos na cadeia produtiva social. A parte prática permitirá o envolvimento participativo e experimental, levando o aluno a ser otimista, alegre e culturalmente sensitivo e poderá utilizar recursos comunitários que beneficiarão a si e ao seu entorno.

Para que esta proposta se consolide de forma produtiva, os recursos a serem utilizados terão um papel fundamental no planejamento das aulas, pois estes nortearão as atividades, que estarão voltadas para os fins estabelecidos. Vale ressaltar a importância da participação constante dos educandos no desenvolvimento das aulas, dando sugestões de elaboração de atividades a partir das necessidades que forem identificando no decurso dos dias.

Permitir estas inferências dos alunos é um aspecto bastante positivo que, se bem planejado e conduzido, permite-lhes identificar algumas necessidades que irão se manifestar durante o desenrolar das aulas. É possível que eles apresentem alguma sugestão que anteriormente não estavam previstas no planejamento, mas que permitirão um crescimento e incremento benéfico da prática pedagógica. 
O contato com os artesãos é um ponto chave nesta proposta e concederá o intercâmbio cultural desejado para a construção dos conceitos sociais que objetivamos e para a percepção do multiculturalismo inserido na proposta. Esse contato será realizado de modo informal e também formal, ambos planejados e com objetivos estabelecidos. O contato informal se dará através da visita à cooperativa e ao espaço de produção dos artesãos, onde os alunos poderão filmar, fotografar, fazer suas próprias perguntas e registrar o que considerarem mais relevante. Em sala de aula, este contato será socializado pela turma para que todos possam compartilhar as impressões vivenciadas durante a visita.

O contato formal se dará por meio de aulas ministradas por artesãos locais. Eles serão convidados para ensinar aos alunos como trabalhar com a fibra de buriti. A proposta é que essa aula aconteça em campo, ou seja, no local de trabalho do convidado. Também serão realizadas entrevistas e pesquisas de elementos referentes à cadeia de produção e comercialização. O professor oferecerá uma ficha para que os alunos pesquisem e preencham, a fim de dar os subsídios mais técnicos para a avaliação dessa forma de fazer arte. Durante a execução dessa proposta será possível investigar aspectos como oferta de matéria prima, instrumentos de produção, preços e custos e valores de comercialização. Essas ações permitirão aos alunos conhecerem as relações de produção e consumo existentes na comercialização artesanal, uma vez que este trabalho objetiva também fornecer idéias exequíveis de alternativa de renda. Nesse tópico, é viável oferecer aos alunos uma palestra sobre empreendedorismo que é viabilizada gratuitamente por profissionais do SEBRAE mediante solicitação prévia.

Após a palestra, os alunos irão realizar suas perguntas ao palestrante, que poderá respondê-las com a propriedade exigida para este assunto. Seguidamente, elaborarão o itinerário produtivo e comercial do artesanato com fibra de buriti.

As percepções estéticas do artesanato escolhido serão apreciadas e trabalhadas pelos alunos, primeiramente através da visualização dos materiais produzidos pelos artesãos, seguidamente, executarão a proposta de elaborarem peças de artesanato, projetadas primeiramente com esboços em desenhos que serão socializados com os colegas e professor em sala para discutir a viabilidade da execução e em seguida, será feita a obtenção da matéria-prima necessária para a execução das peças. 
Depois de elaboradas, as peças serão expostas individualmente pelos alunos em sala de aula, para que comentem sobre o processo de sua idealização e execução, externando seus sentimentos, sua imaginação, enfim, tudo o que gostariam de externar com a peça. Somente depois desse trabalho prévio é que partirão para a feira de comercialização do artesanato produzido por eles, em um evento com a comunidade escolar.

Embora a percepção ecológica não seja a tônica principal desta proposta, é possível que a idéia de desenvolvimento sustentável através da utilização dos recursos naturais pelo homem de forma equilibrada seja trabalhada e incentivada durante a execução das aulas. Sempre é importante que os valores da convivência harmônica entre homem e natureza sejam explorados de forma transversal nas disciplinas, pois isso contribui para a formação integral do pensamento dos educandos, já que a questão da preservação ambiental é muito patente em nossos dias atuais.

Abordar o ensino de artes nessa perspectiva vem se tornando uma metodologia de suma importância. Portanto, a proposta de trabalhá-lo a partir de materiais da fibra de buriti pode parecer uma técnica nova. Contudo, ela está inserida no rol de idéias que defendem a participação da comunidade na vivência em sala de aula, ou ainda, que o ensino de artes não se faz de modo isolado, mas numa interação com o meio em que o aluno vive.

\subsection{A Fibra do Buriti como Técnica de Inovação na Sala de Aula}

O ensino de artes propicia o desenvolvimento de habilidades técnicas artísticas, e, portanto tem uma função importante a cumprir. Ela situa o fazer artístico como fato e necessidade de humanizar o homem histórico, o brasileiro que conhece suas características tanto particulares, tal como se mostram na criação de uma arte brasileira, quanto universais, tal como se revelam no ponto de encontro entre o fazer artístico dos alunos e o fazer dos artistas de todos os tempos, que sempre inauguram formas de tornar presente o inexplicável. Conquanto, é necessário entender a disciplina de artes como um conhecimento fundamental para o 
desenvolvimento integral do aluno, uma vez que o processo de ensino e aprendizagem visa a este desenvolvimento.

Nesse sentido, o Projeto Político Pedagógico da Escola de Ensino Médio Professor Flodoardo Cabral, concebe que "arte compõe a área de Linguagens, Códigos e sua Tecnologias, enquanto linguagem expressivo-comunicativa impregnada de valores culturais e estéticos" (2010, p. 70). Sendo assim, a aceitação da arte como forma de conhecimento humano a ser produzido, apreciado, contextualizado e veiculado através da educação escolar, constitui-se como tentativa de aprimorar a participação dos jovens na sociedade, de fortalecer a construção de sua identidade cultural e de propiciar o desenvolvimento de suas competências gerais, de suas habilidades pessoais e de suas preferências culturais.

Considerando que a proposta de arte no Ensino Médio é desenvolver as linguagens artísticas pelos modos de articulação formal, pelas tecnologias, pelas técnicas, pelos materiais e procedimentos de criação estética e artística, surge a proposta de se trabalhar com a técnica do artesanato em sala de aula.

Assim, esta proposta se torna uma ferramenta muito importante para dinamizar as aulas de artes, haja vista que o aluno poderá ampliar técnicas de artesanato e utilizá-las como um meio de produzir uma renda extra, além do reconhecimento profissional. A arte é um produto da criatividade humana que, utilizando conhecimentos e técnicas e um estilo ou jeito todo pessoal, transmite uma experiência de vida ou uma visão de mundo, despertando emoção em quem usufrui.

A arte trabalhada a partir da fibra da palmeira buriti também pode contribuir, em momento posterior, para o aperfeiçoamento em técnicas mais bem aplicadas que proporcionem resultados satisfatórios que contribuirão ainda mais para o fortalecimento da identidade cultural regional da clientela dessa pesquisa. Isso está de acordo com a visão de Eloí Calage que diz "a arte regional deve ser mais respeitada, para que os artesãos sejam motivados e produzam cada vez mais e com excelente qualidade suas peças de obras de artes" (CALAGE, 2002).

Assim, o artesanato com a fibra do buriti pode ser utilizado como inovação na metodologia do ensino de artes. As atividades artesanais podem ajudar a aumentar a auto-estima de pessoas e até mesmo de comunidades, criando possibilidades para o exercício da cidadania. Além de tudo, essa arte faz com que os indivíduos passem a acreditar em sua capacidade de trabalhar e criar, além de ser uma forma 
de capacitação em ofícios alternativos, que ajudam a complementar a renda da família, como pode ser demonstrado na figura.

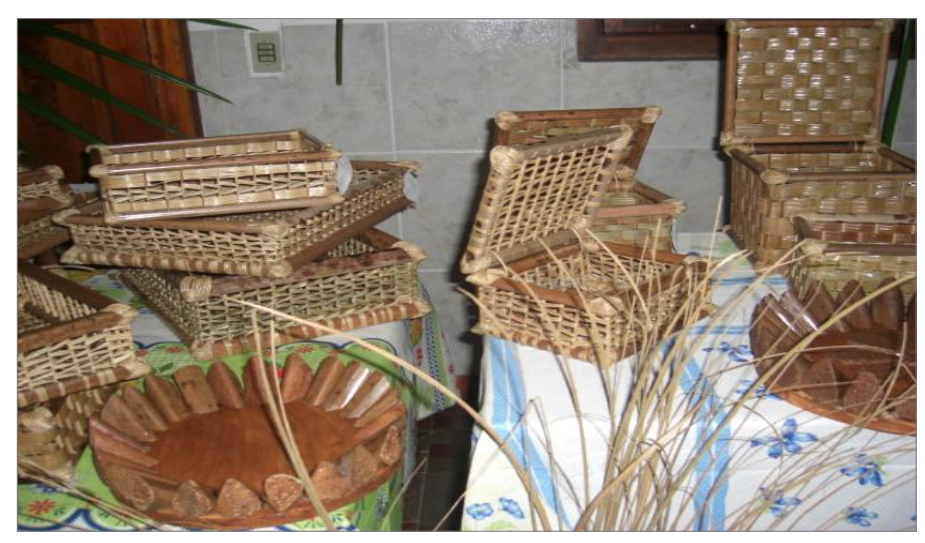

FIG. 1. Proieto: artesanato com fibra de buriti. Educandário de cruzeiro do Sul,

A figura expressa apenas uma das muitas oportunidades do uso da fibra de buriti como atividade artesanal, no entanto, ela tem outras utilidades que podem ser exploradas no ensino de arte. Tudo isso, levando-se em conta que o buriti é uma das mais singulares palmeiras do Brasil e em grande abundância na região norte, principalmente, na cidade de Cruzeiro do Sul - Acre. Na culinária, o buriti é uma fonte de alimento privilegiado, bastante rico em vitamina $A, B$ e $C$, ainda fornece cálcio, ferro e proteínas. Além disso, na cidade, a população tem o hábito tradicional de beber o vinho extraído da sua polpa, mas esta também pode ser transformada em doces, sucos, licores e sobremesas de paladar peculiares.

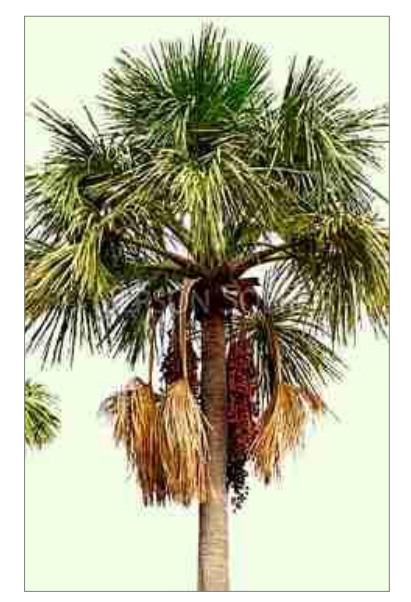

FIG. 2. Fonte: http://www.portalsaofrancisco.com.br/alfa/buriti/imagens/buriti-2.jpg 
Contudo, o óleo extraído da fruta tem valor medicinal para os povos tradicionais indígenas que o utilizam como vermífugo, cicatrizante e energético natural. As substâncias do buriti também dão cor, aroma e qualidade a diversos produtos de beleza, como cremes, xampus, filtro solar e sabonetes. As folhas geram fibras usadas no artesanato, tais como bolsas, tapetes, toalhas de mesa, brinquedos e bijuterias. $O$ talo das folhas serve para a fabricação de móveis. Além de serem leves, as mobílias feitas com o buriti são resistentes e muito bonitas. 


\section{CONSIDERAÇÕES FINAIS}

O uso do artesanato em sala de aula apresentou-se como excelente ferramenta de inovação metodológica, haja vista que o ensino de artes visa ao desenvolvimento da imaginação, percepção e criatividade nas habilidades artísticas e estéticas. $O$ artesanato como técnica muito antiga, que nos dias atuais vem se destacando pela beleza e diversidade de produtos que são possíveis de se criar de forma artesanal, permitiu que surgissem novas idéias de objetos que podem ser confeccionados e apreciados.

Além disso, a arte cria sentidos para ler o cotidiano, apresenta maneiras de superar o comum e aprofundar-se nas idéias sobre o convívio social. Ela é uma possibilidade de criar sentidos ao já posto, de transcender a realidade, abrindo frestas para a imaginação criadora. Assim, foi possível idealizar uma alternativa para o ensino de arte voltada para a integração cultural, o crescimento pessoal e a construção de uma mentalidade democrática, participativa e autônoma. Estes aspectos eram impensáveis há alguns anos devido à visão excessivamente recreativa que imperava no ensino de artes nas escolas, porém, novas formas de se executar este ensino trouxeram novo fôlego a professores e alunos e uma nova forma de enxergar a si e ao outro através da produção artística. Essa magnífica capacidade humana de imaginar permite alterar o cotidiano e encontrar espaços para compreender de outra maneira a realidade que nos cerca.

A proposta mostra-se desafiadora, de um lado, para o educador, no sentido da produção de planos de ensino e sequências didáticas organizadas e flexíveis, que permitam a consecução da gama de objetivos que foram elencados neste trabalho. Do outro lado, favorece também os alunos, que ainda se viam presa a uma forma arcaica e descontextualizada do estudo de artes. Portanto, os ganhos desta proposta estendem-se para ambos, ou seja, enriquece o processo de ensinar e de aprender.

O crescimento dos alunos no desenvolvimento da percepção das relações econômicas na sociedade é de fundamental importância para o aluno do Ensino Médio, visto que nesta etapa da vida, estas preocupações começam a tornar-se mais vívidas em virtude da idade e da necessidade de começarem a compor renda para auxiliar a família. 
Assim, se propõe o uso do artesanato, em particular, da fibra do buriti como forma de inovação do ensino de artes na sala de aula no Ensino Médio, por acreditar que nesta modalidade de ensino os alunos estão consolidando seus conceitos sociais, estão atentos às formas de viver e pensar o mundo e a sociedade e terão contato direto com o mercado de trabalho, carecendo de um ensino objetivamente voltado para a prática inovadora e construtiva. 


\section{Referências Bibliográficas}

BARBOSA, Ana Mae (Org.). Inquietações e mudanças no ensino da arte. 3. Ed. São Paulo: Cortez, 2007.

CALAGE, Eloi. FAJARDO, Elias. JOPPERT, Gilda. Fio e fibras. Rio de Janeiro: Ed. Senac Nacional, 2002.

FUSARI, Maria F. de Rezende. Metodologia do ensino da arte. 2. Ed. São Paulo: Cortez, 1999.

FUSARI, Maria F. de Rezende; FERRAZ, Maria Heloísa C. de T. Arte na educação escolar. 2. Ed. São Paulo: Cortez, 1991.

GODOY, Arilda S. Introdução à pesquisa qualitativa e suas possibilidades. In: revista de Administração de Empresas, v. 35, n. 2, Mar./Abr., 1995.

Lei Federal n. 9394/96 - Estabelece as Diretrizes e Bases da Educação Nacional.

SHANLEY, Patricia. MEDINA, Gabriel. Frutíferas e Plantas Úteis na Vida Amazônica. Belém: Imazon, 2005. 